\title{
Knowledge, attitudes and practices of the Chinese public with respect to coronavirus disease (COVID-19): an online cross- sectional survey
}

Huiming Gao ${ }^{1 \dagger}$, Rujun Hu ${ }^{1,2+}$, Ling Yin², Xiaoli Yuan ${ }^{1}$, Hao Tang ${ }^{2}$, Lan Luo ${ }^{2}$, Mei Chen², Di Huang ${ }^{1}$, Ying Wang ${ }^{1}$, Anyong $\mathrm{Yu}^{2}$ and Zhixia Jiang ${ }^{1 *}$

\begin{abstract}
Background: Coronavirus disease (COVID-19) has become a pandemic. The knowledge, attitudes, and practices (KAP) of the public play a major role in the prevention and control of infectious diseases. The objective of the present study was to evaluate the KAP of the Chinese public and to assess potential influencing factors related to practices.

Methods: A cross-sectional online survey was conducted in China in February 2020 via a self-designed questionnaire comprising 33 questions assessing KAP.

Results: For the 2136 respondents from 30 provinces or municipalities in China, the accurate response rate for the knowledge section ranged from 72.7 to $99.5 \%$, and the average was $91.2 \%$. Regarding attitude section, the percentage of positive attitudes ("strongly agree" and "agree") ranged from 94.7 to $99.7 \%$, and the average value was $98.0 \%$. The good practices ("always" and "often") results ranged from 76.1 to $99.5 \%$, and the average value was 96.8\%. The independent samples t-test revealed that gender and ethnic differences had no effect on knowledge, attitude or behaviour $(P>0.05)$. However, knowledge was associated with age $(t=4.842, p<0.001)$, marital status $(\mathrm{t}=-5.323, p<0.001)$, education level $(\mathrm{t}=8.441, p<0.001)$, occupation $(\mathrm{t}=-10.858, p<0.001)$, and place of residence $(t=7.929, p<0.001)$. Similarly, attitude was associated with marital status $(t=-2.383, p=0.017)$, education level $(t=2.106, p=0.035)$, occupation $(t=-4.834, p<0.001)$, and place of residence $(t=4.242, p<0.001)$. The multiple linear regression analysis results showed that the factors influencing practices were knowledge $(t=-3.281, p=0.001)$, attitude ( $\mathrm{t}=18.756, p<0.001)$, occupation ( $\mathrm{t}=-3.860, p<0.001)$, education level $(\mathrm{t}=3.136, p=0.002)$, and place of residence $(\mathrm{t}=3.257, p=0.001)$.

\footnotetext{
*Correspondence: jzxhl@126.com

${ }^{\dagger}$ Huiming Gao and Rujun Hu contributed equally to this work.

'Department of Nursing, Affiliated Hospital of Zunyi Medical University, Zunyi 563000, Guizhou, China

Full list of author information is available at the end of the article
}

(c) The Author(s). 2020 Open Access This article is licensed under a Creative Commons Attribution 4.0 International License, which permits use, sharing, adaptation, distribution and reproduction in any medium or format, as long as you give appropriate credit to the original author(s) and the source, provide a link to the Creative Commons licence, and indicate if changes were made. The images or other third party material in this article are included in the article's Creative Commons licence, unless indicated otherwise in a credit line to the material. If material is not included in the article's Creative Commons licence and your intended use is not permitted by statutory regulation or exceeds the permitted use, you will need to obtain permission directly from the copyright holder. To view a copy of this licence, visit http://creativecommons.org/licenses/by/4.0/. The Creative Commons Public Domain Dedication waiver (http://creativecommons.org/publicdomain/zero/1.0/) applies to the data made available in this article, unless otherwise stated in a credit line to the data. 
(Continued from previous page)

Conclusions: The Chinese public exhibited a good level of knowledge of COVID-19, a positive attitude, and high adherence to good practices. COVID-19-related knowledge, attitudes and practices were affected by age, marital status, education level, occupation, and place of residence to varying degrees. In addition, practices were affected by knowledge and attitudes towards COVID-19.

Keywords: COVID-19, Knowledge, Attitude, Practice, Survey

\section{Introduction}

Since December 2019, coronavirus disease (COVID-19) has become a pandemic, and patients with confirmed disease and those that are infected but asymptomatic are the main sources of infection [1]. The routes of transmission are diverse and include close contact, droplets from asymptomatic or oligosymptomatic patients and possibly aerosols in health care environments [1], and the population is generally susceptible to infection. According to WHO statistics, as of 23 March 2020, the number of confirmed COVID-19 cases had reached 332, 930 worldwide [2]. Among these cases, 81,601 were in China, and the remaining 251,329 cases were from more than 180 different countries, including Italy, the United States of America, Spain, Germany, and Iran. The disease has resulted in 14,510 deaths so far, and the fatality rate is approximately $4.35 \%$ [2]. Obviously, COVID-19 has become a global public health issue.

Because the population is generally susceptible to COVID-19, it is extremely challenging to prevent and control the spread of this infectious disease. Currently, no vaccine has been developed for COVID-19, and no antiviral drug is specifically recommended. Therefore, applying preventive measures, such as avoiding contact with people with confirmed or suspected infection, practising good hand hygiene, observing respiratory etiquette, and cleaning and disinfecting surfaces, is of utmost importance to reduce the spread of the disease $[3,4]$. The existing literature has indicated that knowledge, attitude and risk perception with respect to infectious diseases are significantly correlated with protective behaviour [5-7], and the behaviours of the public and people in potential risk groups can play a major role in both the prevention and control of infectious diseases [8]. Therefore, it is important to assess the public's knowledge, attitudes, and practices (KAP) regarding COVID-19. However, little is known about the KAP among the Chinese public regarding COVID-19. Specifically, the present study was performed to evaluate KAP among the Chinese public and to assess potential influencing factors related to preventive behaviours. The results of the study can provide information about the effectiveness of the health education efforts of health authorities in China and about how to design evidence-based interventions to reduce the risk of contracting COVID-19.

\section{Methods}

\section{Study design and participants}

This study utilized a cross-sectional online survey conducted on a special questionnaire survey platform (Wenjuanxing, https://www.wjx.cn/) in China. Convenience sampling was used to select potential respondents. The inclusion criteria were (1) $\geq 18$ years old, (2) able to use a smartphone, and (3) able to understand the content of the questionnaire. The exclusion criteria were (1) unable to fill in the questionnaire due to illness or other reasons and (2) unwilling to participate in the research. According to the Kendall sample estimation method for multivariate analysis, the minimum sample size was required to be 10 times the number of variables [9]. The questionnaire applied in the study included 33 variables, and the minimum sample size for this survey was therefore 330 .

\section{Instrument}

Based on the research purpose, the researchers designed the questionnaire themselves (see Additional File 1). The survey consisted of four sections: demographic variables and knowledge, attitudes and practices with respect to COVID-19. The demographic variables included sex, age, ethnicity, marital status, education level, occupation and place of residence. There were 13 items in the knowledge section, and each item contained 3 options, namely, "true", "false" and "don't know"; 1 point was given for a correct answer, and 0 points were awarded for an incorrect answer or a "don't know" response. The total score of this section ranged from 0 to 13 , and higher scores were correlated with more knowledge. The attitude section included five items, and a Likert scale was used to assess the level of agreement with the statements; response options ranged from 1 (strongly disagree) to 5 (strongly agree). The total scores in this section could range from 5 to 25 , and higher scores indicated a more positive attitude. The practices section included 15 items, and a Likert scale was used to assess the level of agreement with the statements; the response options ranged from 1 (never) to 4 (always). The total scores in this section could range from 15 to 60, with higher scores correlating with better protective actions being taken. After the questionnaire draft was designed, a total of 20 public individuals with different 
sociodemographic backgrounds were selected to answer the questionnaire by convenience sampling to test its intelligibility, generalizability and time needed for completion. The content validity index (CVI) of the questionnaire was confirmed by 9 experts on our research team. Before the formal survey, we conducted a pilot study including 50 people to evaluate the internal consistency reliability (Cronbach's $\alpha$ ). Finally, the CVI was 0.94 , and the Cronbach's $\alpha$ value was 0.846 .

\section{Data collection}

The self-designed questionnaire was input into an online questionnaire survey platform (Wenjuanxing, https:// www.wjx.cn/), and the questionnaires were sent to potential respondents through WeChat by convenience sampling in February 2020. Online informed consent was presented to the respondents before they completed the questionnaire.

\section{Statistical analysis}

SPSS version 22.0 (IBM Corp., Armonk, NY, USA) was used for all statistical analyses. The categorical data are described by frequencies and composition ratios. The continuous data are described as the means and standard deviations. The t-test was used to analyse KAP differences in regards to COVID-19 among groups with different demographic characteristics. Multiple linear regression analysis was used to explore the factors influencing the public's COVID-19 prevention practices. All statistical tests were two-sided, with $p \leq 0.05$ indicating statistical significance.

\section{Results}

\section{Participant sociodemographic information}

A total of 2136 survey responses from 30 provinces or municipalities in China were received. The top five participating provinces and municipalities were Guizhou (1701, 79.6\%), Chongqing (165, 7.7\%), Sichuan (130, 6.1\%), Hubei (30, 1.4\%), and Henan (25, 1.2\%). The sociodemographic details of the 2136 participants are summarized in Table 1.

\section{Knowledge of the public regarding COVID-19}

The accurate response rate for the knowledge section ranged from $72.7 \%$ (family gatherings may spread infection) to $99.5 \%$ (most people infected present with fever, fatigue, and dry cough as the main symptoms), and the average accuracy rate was $91.2 \%$. The accurate response rate was greater than $80 \%$ for all items except for "family gatherings may spread infection" and "a suspected case can be ruled only out after two consecutive negative tests of respiratory pathogenic nucleic acid (at least one day apart)" as shown in Table 2.
Table 1 Sociodemographic information of the participants $(N=2136)$

\begin{tabular}{|c|c|}
\hline Variable & $\mathrm{n}(\%)$ or Mean \pm SD \\
\hline \multicolumn{2}{|l|}{ Sex } \\
\hline Male & $467(21.9)$ \\
\hline Female & $1669(78.1)$ \\
\hline Age (year) & $33.1 \pm 8.8$ \\
\hline \multicolumn{2}{|l|}{ Ethnicity } \\
\hline Han & $1830(85.7)$ \\
\hline Other & $306(14.3)$ \\
\hline \multicolumn{2}{|l|}{ Marital status } \\
\hline Married & $1473(69.0)$ \\
\hline Unmarried & $593(27.8)$ \\
\hline Divorced & $65(3.0)$ \\
\hline Widowed & $5(0.2)$ \\
\hline \multicolumn{2}{|l|}{ Education level } \\
\hline Middle school and below & $94(4.4)$ \\
\hline High school/technical secondary school & $113(5.3)$ \\
\hline Junior college & $333(15.6)$ \\
\hline Bachelor's degree & $1259(58.9)$ \\
\hline Master's degree and above & $337(15.8)$ \\
\hline \multicolumn{2}{|l|}{ Occupation } \\
\hline Medical staff & $1228(57.5)$ \\
\hline Worker & $34(1.6)$ \\
\hline Farmer & $23(1.1)$ \\
\hline Self-employed & $120(5.6)$ \\
\hline Student & $176(8.2)$ \\
\hline Employee of an enterprise or institution & $393(18.4)$ \\
\hline Unemployed or retired & $33(1.5)$ \\
\hline Other & $129(6.0)$ \\
\hline \multicolumn{2}{|l|}{ Place of residence } \\
\hline City & $1740(81.5)$ \\
\hline Countryside or town & $396(18.5)$ \\
\hline
\end{tabular}

$S D$ standard deviation

\section{Attitude of the public towards COVID-19}

The proportion of positive attitudes (strongly agree and agree) ranged from $94.7 \%$ (It is believed that the outbreak will soon be contained) to $99.7 \%$ (I am willing to cooperate with the relevant departments to take prevention and control measures), and the average value was 98.0\%, as shown in Table 3.

\section{Practices of the public with respect to COVID-19}

The proportion of good practices (always and often) ranged from $76.1 \%$ (home environment disinfection) to 99.5\% (wash hands), and the average value was $96.8 \%$. The good practice adherence rate of all items was more than $80 \%$ except for "monitor body temperature", 
Table 2 Knowledge level of respondents regarding COVID-19 $(N=2136)$

\begin{tabular}{|c|c|}
\hline Items & $\begin{array}{l}\text { Accuracy } \\
\mathrm{n}(\%)\end{array}$ \\
\hline 1. The source of infection is primarily confirmed and asymptomatic patients & $1919(89.8)$ \\
\hline 2.Transmission mainly occurs through respiratory droplets and close contact & $2108(98.7)$ \\
\hline 3. The population is generally susceptible to infection & $2001(93.7)$ \\
\hline 4. It is highly infectious and spreads quickly & $2121(99.3)$ \\
\hline 5. Washing hands frequently, wearing masks and other measures can effectively prevent infection & $2115(99.0)$ \\
\hline 6. Family gatherings may spread infection & $1553(72.7)$ \\
\hline 7. The incubation time of the disease is $1-14$ days, typically $3-7$ days & $2056(96.3)$ \\
\hline 8. Most people infected present with fever, fatigue, and dry cough as the main symptoms & $2125(99.5)$ \\
\hline 9. Most patients have a good prognosis, while a few are in critical condition & $1875(87.8)$ \\
\hline $\begin{array}{l}\text { 10. A suspected case can be ruled only out after two consecutive negative tests of respiratory } \\
\text { pathogenic nucleic acid (at least } 1 \text { day apart) }\end{array}$ & $1659(77.7)$ \\
\hline $\begin{array}{l}\text { 11. Suspected and confirmed patients should be isolated and treated in designated hospitals } \\
\text { with effective isolation and protective conditions }\end{array}$ & $2111(98.8)$ \\
\hline 12. If you develop a fever during the outbreak, you can take your own medicine & $1779(83.3)$ \\
\hline 13. Medical alcohol at a concentration of $75 \%$ can effectively inactivate the virus & 1911 (89.5) \\
\hline Average accuracy & 91.2 \\
\hline
\end{tabular}

"appropriate exercise", and "home environment disinfection", as shown in Table 4.

\section{Single-factor analysis of the factors influencing knowledge, attitudes and practices}

Independent samples t-test analysis indicated that gender and ethnic differences had no effect on KAP. The knowledge score of the <32-year-old group was lower than that of the $\geq 32$-year-old group, and the difference was statistically significant. Marital status, education level, occupation and place of residence all had impacts on the KAP scores, and the differences were statistically significant, as shown in Table 5.

\section{Multiple linear regression analysis of the factors influencing practice $(N=2136)$}

The statistically significant indicators of knowledge and attitudes from the results of the single-factor analysis were incorporated into the multifactor model. With the practices score as the dependent variable, marital status
$($ married $=1, \quad$ single $/$ widowed $/$ divorced $=2)$, education (below junior college $=1$, college degree and above $=2$ ), occupation (medical staff $=1$, other professions $=2$ ), place of residence (city $=1$, countryside/town $=2$ ), knowledge (continuous variable), and total attitude score (continuous variable) were the six independent variables. Multiple linear regression was conducted by the stepwise entry method with a selection level of 0.05 and an elimination level of 0.10 . The results showed that the regression model was statistically significant $(F=104.141, P<$ 0.001 , adjusted $R^{2}=0.195$ ), and the five independent variables included in the model had statistically significant effects on practice $(P<0.05)$, as shown in Table 6 .

\section{Discussion}

The current study was conducted to assess and compare the KAP scores of different population groups with respect to COVID-19 in China. This evaluation was essential to improve protective practices for preventing COVID-19 infection among the public because no

Table 3 The public's attitude towards COVID-19 $(N=2136)$

\begin{tabular}{|c|c|c|c|c|c|}
\hline Items & $\begin{array}{l}\text { Strongly agree } \\
\mathrm{n}(\%)\end{array}$ & $\begin{array}{l}\text { Agree } \\
\mathrm{n}(\%)\end{array}$ & $\begin{array}{l}\text { Not sure } \\
\mathrm{n}(\%)\end{array}$ & $\begin{array}{l}\text { Disagree } \\
\mathrm{n}(\%)\end{array}$ & $\begin{array}{l}\text { Strongly disagree } \\
\mathrm{n}(\%)\end{array}$ \\
\hline 1. I pay close attention to the development of the epidemic situation & $1995(93.4)$ & $134(6.3)$ & $4(0.2)$ & $0(0)$ & $3(0.1)$ \\
\hline 2. I think I am playing an important role in controlling the epidemic & $1754(82.1)$ & $340(15.9)$ & $38(1.8)$ & $2(0.1)$ & $2(0.1)$ \\
\hline 3. I fear infection for myself and my family & $1809(84.7)$ & $273(12.8)$ & $41(1.9)$ & $7(0.3)$ & $6(0.3)$ \\
\hline 4. It is believed that the outbreak will soon be contained & $1699(79.5)$ & $325(15.2)$ & $96(4.5)$ & $11(0.5)$ & $5(0.2)$ \\
\hline $\begin{array}{l}\text { 5. I am willing to cooperate with the relevant departments to take } \\
\text { prevention and control measures }\end{array}$ & $1956(91.6)$ & $172(8.1)$ & $5(0.2)$ & $0(0)$ & $2(0.1)$ \\
\hline Average rate & 86.3 & 11.7 & 1.7 & 0.2 & 0.2 \\
\hline
\end{tabular}


Table 4 The public's COVID-19 prevention practices $(N=2136)$

\begin{tabular}{|c|c|c|c|c|}
\hline Items & $\begin{array}{l}\text { Always } \\
\mathrm{n}(\%)\end{array}$ & $\begin{array}{l}\text { Often } \\
\text { n (\%) }\end{array}$ & $\begin{array}{l}\text { Sometimes } \\
\mathrm{n}(\%)\end{array}$ & $\begin{array}{l}\text { Never } \\
\text { n (\%) }\end{array}$ \\
\hline 1. After the outbreak, stay at home to prevent infection & $1752(82.0)$ & $301(14.1)$ & $63(2.9)$ & $20(0.9)$ \\
\hline 2. Wear a mask when going out & $2072(97.0)$ & $51(2.4)$ & $9(0.4)$ & $4(0.2)$ \\
\hline 3. Wash hands & $1970(92.2)$ & $155(7.3)$ & $10(0.5)$ & $0(0)$ \\
\hline 4. Seek medical advice when symptoms such as fever and cough appear & $1870(87.5)$ & $161(7.5)$ & $90(4.2)$ & $15(0.7)$ \\
\hline 5. Monitor body temperature & $1273(59.6)$ & $406(19.0)$ & $353(16.5)$ & $104(4.9)$ \\
\hline 6. Open windows to keep the air fresh & $1823(85.3)$ & $280(13.1)$ & $32(1.5)$ & $0(0)$ \\
\hline 7. Rest properly and don't stay up late & $1498(70.1)$ & $385(18.0)$ & $229(10.7)$ & $24(1.1)$ \\
\hline 8. Appropriate exercise & $1287(60.3)$ & $406(19.0)$ & $407(19.1)$ & $36(1.7)$ \\
\hline 9. Home environment disinfection & $1104(51.7)$ & $522(24.4)$ & $448(21.0)$ & $62(2.9)$ \\
\hline 10. Reduce time in airtight, airless environments & $1780(83.3)$ & $244(11.4)$ & $54(2.5)$ & $58(2.7)$ \\
\hline 11. Reduce visits to crowded places & $1831(85.7)$ & $218(10.2)$ & $43(2.0)$ & $44(2.1)$ \\
\hline $\begin{array}{l}\text { 12. Avoid direct contact with public facilities that may be infected, } \\
\text { such as elevator buttons and stair railings }\end{array}$ & $1673(78.3)$ & $323(15.1)$ & $107(5.0)$ & $33(1.5)$ \\
\hline 13. Active quarantine after contact with high-risk groups & $1923(90.0)$ & $143(6.7)$ & $44(2.1)$ & $26(1.2)$ \\
\hline 14. Cover mouth and nose when coughing or sneezing & $1944(91.0)$ & $162(7.6)$ & $20(0.9)$ & $10(0.5)$ \\
\hline 15. Keep warm and avoid catching cold & $1965(92.0)$ & $161(7.5)$ & $6(0.3)$ & $4(0.2)$ \\
\hline Average rate & 87.4 & 9.4 & 2.1 & 1.1 \\
\hline
\end{tabular}

vaccine is available and no specific treatment is being offered against the disease at present. In our study, 2136 people participated, and the response efficiency was $100 \%$.

The results of this study revealed that the Chinese public has good knowledge of COVID-19, with an overall correct response rate of $91.2 \%$. This result may be attributed to the demographic characteristics of the participants $(90.3 \%$ junior college degree or higher, $57.5 \%$ medical staff, and $81.5 \%$ urban residents) because significant associations between these demographic variables and KAP towards COVID-19 were verified in the present study. This result coincides with those of other similar studies performed among public and healthcare professionals in China and abroad [10-14]. The result was expected because Chinese governmental offices at all levels have released relevant education materials in a timely manner and have delivered COVID-19-related content through various channels, including television, the internet, WeChat, and publicity boards, since the outbreak began. The accuracy rate of 11 items ranged between 83.3 and 99.5\%, with two items falling below this range, "family gatherings may spread infection" and "a suspected case can be ruled only out after two consecutive negative tests of respiratory pathogenic nucleic acid (at least one day apart)". On the one hand, this result implies that the public has incomplete knowledge of COVID-19, especially regarding some professional topics, and still needs further education. On the other hand, this infectious disease has caused infection within family groups $[15,16]$. Hence, health authorities should further increase publicity to raise public awareness of the disease.

In the present study, participants showed extremely positive attitudes towards COVID-19. A total of 99.7\% of the public paid close attention to the development of the epidemic situation, $98.0 \%$ thought they played an important role in controlling the epidemic, $94.7 \%$ believed that the outbreak would soon be contained, and $99.7 \%$ expressed willingness to cooperate with the relevant departments to take prevention and control measures. The results are similar to those of other published studies [10, 17-19], likely because the Chinese government at different levels has attached great importance to the epidemic and adopted strict prevention and control measures in a timely manner against the disease after the outbreak [20]. In addition, with the COVID-19 pandemic and media reports, the Chinese public understands the severity of the epidemic. Therefore, they desire to actively participate in epidemic prevention and control. In addition, $97.5 \%$ of the public expressed fear of infection for themselves and their families, indicating that health authorities should continue to organize corresponding health education and publicity to prevent fear of spreading.

The majority of the public adhered to good practices with respect to COVID-19 infection, potentially because they had good COVID-19 knowledge and a positive attitude, which ultimately translates into good practice. However, the least common practice among participants 
Table 5 Univariate analysis of the factors influencing knowledge, attitudes and practices $(N=2136)$

\begin{tabular}{|c|c|c|c|c|c|}
\hline Items & Number & Statistical value & $\begin{array}{l}\text { Knowledge } \\
(\text { mean } \pm \text { SD) }\end{array}$ & $\begin{array}{l}\text { Attitudes } \\
(\text { mean } \pm \text { SD) }\end{array}$ & $\begin{array}{l}\text { Practices } \\
(\text { mean } \pm S D)\end{array}$ \\
\hline \multicolumn{6}{|l|}{ Sex } \\
\hline Male & 467 & & $11.78 \pm 1.30$ & $24.16 \pm 1.61$ & $55.37 \pm 5.24$ \\
\hline \multirow[t]{3}{*}{ Female } & 1669 & & $11.88 \pm 1.15$ & $24.19 \pm 1.54$ & $55.86 \pm 4.93$ \\
\hline & & $\mathrm{t}$ & -1.593 & -0.406 & -1.782 \\
\hline & & $P$ & 0.112 & 0.685 & 0.075 \\
\hline \multicolumn{6}{|l|}{ Age (year) ${ }^{a}$} \\
\hline$<32$ & 999 & & $11.73 \pm 1.22$ & $24.21 \pm 1.70$ & $55.87 \pm 5.23$ \\
\hline \multirow[t]{3}{*}{$\geq 32$} & 1137 & & $11.98 \pm 1.34$ & $24.16 \pm 1.41$ & $55.65 \pm 4.80$ \\
\hline & & $\mathrm{t}$ & 4.842 & -0.700 & -0.999 \\
\hline & & $P$ & $<0.001$ & 0.484 & 0.318 \\
\hline \multicolumn{6}{|l|}{ Ethnicity } \\
\hline Han & 1830 & & $11.87 \pm 1.16$ & $24.17 \pm 1.53$ & $55.75 \pm 4.94$ \\
\hline \multirow[t]{3}{*}{ Other } & 306 & & $11.77 \pm 1.30$ & $24.28 \pm 1.70$ & $55.76 \pm 5.40$ \\
\hline & & $\mathrm{t}$ & 1.365 & -1.164 & -0.036 \\
\hline & & $P$ & 0.173 & 0.245 & 0.971 \\
\hline \multicolumn{6}{|l|}{ Marital status } \\
\hline Married & 1473 & & $11.96 \pm 1.10$ & $24.23 \pm 1.43$ & $55.93 \pm 4.75$ \\
\hline \multirow[t]{3}{*}{ Unmarried or divorced or widowed } & 663 & & $11.64 \pm 1.32$ & $24.07 \pm 1.79$ & $55.35 \pm 5.52$ \\
\hline & & $\mathrm{t}$ & -5.323 & -2.383 & -2.101 \\
\hline & & $P$ & $<0.001$ & 0.017 & 0.036 \\
\hline \multicolumn{6}{|l|}{ Education level } \\
\hline Below junior college & 207 & & $11.01 \pm 1.56$ & $23.97 \pm 1.71$ & $53.53 \pm 6.32$ \\
\hline \multirow[t]{3}{*}{ Junior college and above } & 1929 & & $11.95 \pm 1.10$ & $24.21 \pm 1.53$ & $55.99 \pm 4.78$ \\
\hline & & t & 8.441 & 2.106 & 6.803 \\
\hline & & $P$ & $<0.001$ & 0.035 & $<0.001$ \\
\hline \multicolumn{6}{|l|}{ Occupation } \\
\hline Medical staff & 1228 & & $12.11 \pm 0.93$ & $24.33 \pm 1.32$ & $56.53 \pm 4.27$ \\
\hline \multirow[t]{3}{*}{ Other } & 908 & & $11.53 \pm 1.39$ & $23.99 \pm 1.80$ & $54.70 \pm 5.69$ \\
\hline & & $\mathrm{t}$ & -10.858 & -4.834 & -8.497 \\
\hline & & $P$ & $<0.001$ & $<0.001$ & $<0.001$ \\
\hline \multicolumn{6}{|l|}{ Place of residence } \\
\hline City & 1740 & & $11.98 \pm 1.05$ & $24.27 \pm 1.38$ & $56.14 \pm 4.56$ \\
\hline \multirow[t]{3}{*}{ Countryside or town } & 396 & & $11.34 \pm 1.54$ & $23.80 \pm 2.13$ & $54.03 \pm 6.33$ \\
\hline & & t & 7.929 & 4.242 & 6.272 \\
\hline & & P & $<0.001$ & $<0.001$ & $<0.001$ \\
\hline
\end{tabular}

The median age of the subjects was 32 years

Table 6 Multiple linear regression analysis of the factors influencing practice

\begin{tabular}{|c|c|c|c|c|c|}
\hline Variable & Partial regression coefficient $(\mathrm{B})$ & Standard error (SE) & Standardized partial regression coefficient (beta) & $\mathrm{t}$ & $\mathbf{P}$ \\
\hline Constant & 23.537 & 2.009 & - & 11.716 & $<0.001$ \\
\hline Attitude score & 1.195 & 0.064 & 0.371 & 18.756 & $<0.001$ \\
\hline Occupation & -0.838 & 0.217 & -0.083 & -3.860 & $<0.001$ \\
\hline Knowledge score & 0.286 & 0.087 & 0.068 & 3.281 & 0.001 \\
\hline Place of residence & -0.867 & 0.266 & -0.067 & -3.257 & 0.001 \\
\hline Education level & 1.130 & 0.360 & 0.067 & 3.136 & 0.002 \\
\hline
\end{tabular}


was "home environment disinfection". Perhaps the shortage of protective equipment, such as medical alcohol and chlorine-containing disinfectants, during the outbreak made it difficult to disinfect the home environment. This result suggests that during infectious disease outbreaks, government departments should try their best to provide sufficient supplies of protective equipment so that the public can take protective actions.

Further analysis found that age was a factor influencing the public's grasp of COVID-19. The population younger than 32 years old (the median age of the study subjects) had less knowledge than their counterparts, which is potentially attributed to the increases in social experience and knowledge reserves with age. Marital status, education, occupation, and place of residence all had impacts on KAP. Married people had a better grasp of knowledge, more active protective attitudes, and higher adherence rates to protective behaviours than unmarried, divorced, or widowed individuals. This may be because married people have the responsibility of caring for their families in addition to self-protection. Therefore, they tend to learn more about protection, have a more positive attitude, and engage in proactive protective actions. People with a college degree or above had better KAP than their counterparts. Higher degrees may correlate with broader knowledge and a stronger learning ability, making it easier to grasp the relevant knowledge regarding COVID-19, adopt a protective attitude and be more positive. It has been suggested that health education should be targeted at people with different educational levels and different needs for health education. For the less educated population, easy-to-understand publicity materials may be more effective [21]. Medical personnel had more knowledge, better attitudes, and higher behaviour scores than nonmedical respondents because medical personnel generally have a college degree or higher and have received more professional medical training. Hence, in the process of preventing and controlling COVID-19, the average person needs more education on knowledge regarding COVID19 than medical staff. Compared with rural or urban residents, those living in cities had higher KAP scores, which was potentially due to the following reasons. (a) Information sources are more available and spread faster in cities, and people can obtain first-hand information quickly [22]. (b) The cultural literacy of city residents is generally higher than that of people living in rural or urban areas [23]. (c) The composition of people in the city is more complex, and the population density is high, which increases the likelihood of COVID-19 dissemination. As a result, citizens are more proactive in epidemic prevention. (d) Medical and protective supplies in cities are more abundant than in rural areas, and citizens thus have more opportunities to obtain relevant protective supplies and take protective action.
In mastering the basic knowledge on COVID-19 prevention and control, the ultimate goal is application in practice, i.e., to be able to properly take protective measures, control the roots of infection, cut off the transmission route, and protect vulnerable groups. Multiple linear regression analysis results showed that knowledge, attitude, occupation, education level, and place of residence were the main factors affecting the public's protective behaviour. According to the KAP model, knowledge is the basis and attitude is the driving force of behaviour change [24]. Therefore, improving people's knowledge and fostering positive attitudes towards epidemic prevention are indispensable for improving protective behaviour to fight against the COVID-19 pandemic. Moreover, this result indicates that it is necessary to take targeted measures to improve people's protective behaviour effectively based on their profession, education level and area of residence, especially for nonmedical staff, people with low levels of education, and township villagers. These results can be used by health policymakers to develop more targeted policies to fight against the COVID-19 pandemic.

This study has several limitations. First, while we conducted this non-random sampling online survey involving 30 provinces or municipalities by convenience sampling, nearly $80 \%$ of the respondents came from Guizhou Province, and the composition of the samples was uneven, mainly including females, medical staff (who have a high education level), city residents and young people. Therefore, the generalizability of the research results has certain limitations. In addition, this study was based on selfreported information about knowledge, attitudes and practices with respect to COVID-19. It is possible that participants looked up the answers before answering some of the questions, which may have exaggerated the accuracy rate of COVID-19 knowledge. To alleviate this bias, we made the questionnaire anonymous and emphasized anonymity during the survey, and we stressed the importance of answering questions honestly before completing the questionnaire. Last, cross-sectional studies are unable to provide evidence on causality. Therefore, the mechanisms for improving COVID-19 protection practices need to be further explored.

\section{Conclusion}

In summary, the public in China has a good grasp of the relevant knowledge on COVID-19, positive attitudes, and high adherence rates with respect to protective behaviours. Practices are affected by knowledge, attitudes, occupation, education, and place of residence. 


\section{Supplementary Information}

The online version contains supplementary material available at https://doi. org/10.1186/s12889-020-09961-2

\section{Additional file 1.}

\section{Abbreviations}

COVID-19: Coronavirus disease; KAP: Knowledge, attitudes, and practices; WHO: World Health Organization; CVI: Content validity index; SD: Standard deviation

\section{Acknowledgements}

We would like to thank the participants for their sincere support and

American Journal Experts (AJE) for editing a draft of this manuscript.

\section{Authors' contributions}

$R J H, H M G, L Y, H T, L L, M C, D H$ and $Y W$ were responsible for conceiving and designing the experiments, collecting and analysing the data, and writing and revising the manuscript. RJH, XLY and ZXJ were responsible for the data interpretation. ZXJ and AYY made important intellectual contributions to the research design, provided technical guidance and revised the manuscript HMG and RJH contributed equally to this paper. All the authors read and approved the final version of the manuscript.

\section{Funding}

Not applicable.

\section{Availability of data and materials}

The datasets used and/or analysed during the current study are available from the corresponding author upon reasonable request.

\section{Ethics approval and consent to participate}

The study was reviewed and approved by the Biomedical Research Ethics Committee of the Affiliated Hospital of Zunyi Medical University (KLL-2020010). Online informed consent was provided by the respondents before they completed the questionnaire.

\section{Consent for publication}

All authors agreed to the publication of the manuscript.

\section{Competing interests}

The authors have no competing interests to declare.

\section{Author details}

'Department of Nursing, Affiliated Hospital of Zunyi Medical University, Zunyi 563000, Guizhou, China. '2Department of Emergency, Affiliated Hospital of Zunyi Medical University, Zunyi 563000, Guizhou, China.

Received: 3 July 2020 Accepted: 22 November 2020

Published online: 30 November 2020

\section{References}

1. China National Health Commission: Diagnosis and treatment of COVID-19 in China (version 7); 2020

2. WHO. Coronavirus disease (COVID-2019) situation reports-63. 2020.

3. Chinese Center For Disease Prevent. Guidelines for public protection against COVID-19. Version 1 ed. Beijing: People's Medical Publishing House; 2020.

4. Al-Hazmi A, Gosadi I, Somily A, Alsubaie S, Bin SA. Knowledge, attitude and practice of secondary schools and university students toward Middle East respiratory syndrome epidemic in Saudi Arabia: a cross-sectional study. Saudi J Biol Sci. 2018;25(3):572-7.

5. Goodwin R, Haque S, Neto F, Myers LB. Initial psychological responses to influenza A, H1N1 ("swine flu"). BMC Infect Dis. 2009;9:166.

6. Ma XW, Liu YF, Yuan J, Liu JP, Xie CJ, Liu YH, Chen JD, Feng J, Di B. An analysis of the knowledge, attitudes and behaviors among live poultry traders during the early wave outbreak of human infected Avian influenza A(H7N9) in Guangzhou City, China. Chin J Dis Control Prev. 2015;19(6):593-6.

7. Seale H, Heywood AE, McLaws ML, Ward KF, Lowbridge CP, Van D, Maclntyre CR. Why do I need it? I am not at risk! Public perceptions towards the pandemic (H1N1) 2009 vaccine. BMC Infect Dis. 2010;10:99.
8. de Zwart O, Veldhuijzen IK, Elam G, Aro AR, Abraham T, Bishop GD, Voeten HA, Richardus JH, Brug J. Perceived threat, risk perception, and efficacy beliefs related to SARS and other (emerging) infectious diseases: results of an international survey. Int J Behav Med. 2009;16(1):30-40.

9. Wang JL. Clinical epidemiology-design, measurement and evaluation of clinical scientific research (version 3). Shanghai: Shanghai Scientific and Technical Publishers; 2009

10. Cai HL, Zhu YX, Lei LB, Pan CH, Zhu LW, Li JH, Gu J, Hao YT. Novel coronavirus pneumonia epidemic-related knowledge, behaviors and psychology status among college students and their family members and friends: an internet-based cross-sectional survey. Chin J Public Health. 2020; 36(2):152-5

11. Geldsetzer P. Knowledge and perceptions of COVID-19 among the general public in the United States and the United Kingdom: a cross-sectional online survey. Ann Intern Med. 2020;173(2):157-60.

12. Papagiannis D, Malli F, Raptis DG, Papathanasiou IV, Fradelos EC, Daniil Z, Rachiotis G, Gourgoulianis Kl. Assessment of knowledge, attitudes, and practices towards new coronavirus (SARS-CoV-2) of health care professionals in Greece before the outbreak period. Int J Environ Res Public Health. 2020; 17(14):4925.

13. Galle F, Sabella EA, Da MG, De Giglio O, Caggiano G, Di Onofrio V, Ferracuti S, Montagna MT, Liguori G, Orsi GB, et al. Understanding knowledge and behaviors related to CoViD-19 epidemic in Italian undergraduate students: the EPICO study. Int J Environ Res Public Health. 2020;17(10):3481.

14. Zhong BL, Luo W, Li HM, Zhang QQ, Liu XG, Li WT, Li Y. Knowledge, attitudes, and practices towards COVID-19 among Chinese residents during the rapid rise period of the COVID-19 outbreak: a quick online crosssectional survey. Int J Biol Sci. 2020;16(10):1745-52.

15. Chan JF, Yuan S, Kok KH, To KK, Chu H, Yang J, Xing F, Liu J, Yip CC, Poon RW, et al. A familial cluster of pneumonia associated with the 2019 novel coronavirus indicating person-to-person transmission: a study of a family cluster. Lancet. 2020;395(10223):514-23.

16. Oian G, Yang N, Ma A, Wang L, Li G, Chen X, Chen X. A COVID-19 transmission within a family cluster by presymptomatic infectors in China. Clin Infect Dis. 2020;71(15):861-2

17. Li WH, Liu B, Liu M, Zhao XH, Chen QS. Investigation and analysis of public cognition and prevention awareness of Corona Virus Disease 2019 inside and outside Hubei Province. J Jinan Univ. 2020;41(2):186-93.

18. Luo L, Zeng XJ, Liao X, Yang YQ. Disease cognition, coping style and exercise behavior among the public during novel coronavirus epidemic: an online survey. Chin J Public Health. 2020;36(2):156-9.

19. Zhu YC, Feng HW, Luo YZ, He TF, Lou WW. Knowledge, attitude and practice of coronavirus disease 2019 in Ningbo residents. Prev Med. 2020; 32(3):230-4.

20. Cheng V, Wong SC, To K, Ho PL, Yuen KY. Preparedness and proactive infection control measures against the emerging novel coronavirus in China. J Hosp Infect. 2020;104(3):254-5.

21. Shi R, Cai Y, Zeng W, Wang Y. A KAP survey to the severe acute respiratory syndrome in Shanghai residents. Chin Gen Pract. 2003;6(6):481-5.

22. Xu YF, Li P, Zhou J, Guo LF. Investigation on cognitive behavior and psychological status of SARS in residents of Nanning city. Pract Prev Med. 2005;12(1):134-5.

23. Feng J, Li TG, Qin PZ, Lu JY, Chen C, Chen ZQ, Yang ZC. Telephone survey and analysis of flu among citizens in Guangzhou. S China J Prev Med. 2013; 39(4):35-7.

24. Li WY, L J, Yu GL, Xu JH. Application of the knowledge-belief-practice model in nursing practice:current status and prospects. J Nurs Sci. 2015;30(6):107-10.

\section{Publisher's Note}

Springer Nature remains neutral with regard to jurisdictional claims in published maps and institutional affiliations. 